\title{
Injury risk of playing football in Futsal World Cups
}

\author{
Astrid Junge, Jiri Dvorak ${ }^{1,2}$
}

${ }^{1}$ FIFA Medical Assessment and Research Center (F-MARC) and Schulthess Klinik, Zurich, Switzerland

${ }^{2}$ Fédération Internationale de Football Association (FIFA),

Zurich, Switzerland

\section{Correspondence to}

Dr Astrid Junge, Schulthess

Klinik, F-MARC, Lengghalde 2 ,

CH-8008 Zurich, Switzerland; medical@fifa.org

Accepted 4 September 2010

Published Online First

19 October 2010

\section{(6) UNLOCKED}

This paper is freely available online under the BMJ Journals unlocked scheme, see http:// bjsm.bmj.com/info/unlocked.dtl

\section{ABSTRACT}

Background While injuries in football (soccer) have been the subject of numerous publications, little information is available about the injury risk in futsal.

Objective Analysis of the incidence and characteristics of injury in futsal players during top-level international tournaments.

Design Prospective survey.

Methods Player injuries during three consecutive Futsal World Cups were analysed using an established injury report system. The physicians of all participating teams reported all injuries after each match on a standardised injury report form. The average response rate was $93 \%$.

Results A total of 165 injuries were reported from 127 matches, which is equivalent to an incidence of 195.6 injuries per 1000 player hours (95\% Cl 165.8 to 225.6 ) or 130.4 injuries per 1000 player matches $195 \%$ $\mathrm{Cl} 110.5$ to 150.3). The majority of injuries were caused by contact with another player, and $36 \%$ of the injuries occurred during non-contact activities. Most injuries affected the lower extremity (70\%), followed by head and neck (13\%), upper extremity (10\%) and trunk (7\%). The most frequent diagnoses were contusion of the lower leg $(11 \%)$, ankle sprain $(10 \%)$ and groin strain $(8 \%)$. On average, one time-loss injury in every two matches was reported.

Conclusion While the location and diagnosis of injuries were similar in the two types of football, fewer injuries in futsal than in football were caused by contact with another player and by foul play. More information on injury mechanisms in futsal is needed to develop specific injury preventive interventions.

\section{INTRODUCTION}

Futsal is the five-a-side version of football played on a smaller pitch and usually indoors. It is played by over a million registered players worldwide (http://www.fifa.com/mm/document/fifafacts/ bcoffsurv/bigcount.summaryreport_7022.pdf) and is a growing sport in many countries. It started in South America in 1930 and the first World Futsal Championship was held 1982 in Brazil. Since 1989, a Futsal World Cup is organised by the Fédération Internationale de Football Association (FIFA). The important differences in the laws of the game between football and futsal are listed in table 1.

A few scientific studies have been published on match demands and fitness parameters of futsal players. ${ }^{1-5}$ From the analyses of heart rates and time-motion during competitive matches, the authors concluded that futsal is a multiple-sprints sport with more highintensity phases than football. ${ }^{4}$ While injuries in football have been the subject of numerous publications, ${ }^{6} 7$ only two studies on injuries in futsal were found in the literature. ${ }^{8}{ }^{9}$ In a recent national survey on sports injuries in The Netherlands, ${ }^{8}$ futsal was among the top 10 sports that contributed most to the absolute number of sports injuries and had the highest injury incidence per $10000 \mathrm{~h}$ of sports participation (55.2; 95\% CI 42.7 to 71.3$)$. The injury rate was about 2.7 times higher than in football (20.3; 95\% CI 18.4 to 22.4$)$, but it seems that the populations participating in futsal and in football differed in age and gender.

Futsal is different from indoor football (indoor soccer), which is more common in the USA and Canada. The most important differences are that a team includes six players, and the ball can be played directly off the wall that surrounds the playing field. Few studies on injuries in indoor soccer have been published. ${ }^{10-14}$ The comparison of injury rates in indoor and outdoor football had inconsistent results. ${ }^{10} 14$

The aim of this study was to analyse the incidence and characteristics of injury during Futsal World Cups and compare the results with the equivalent outdoor tournament (FIFA World Cup ${ }^{\mathrm{TM}}$ ).

\section{METHODS}

The injury surveillance system applied is well established in international footbal1 ${ }^{15}$ and other team sports ${ }^{16} 17$ competitions. Since 1998 it has been implemented routinely in more than 40 international football tournaments. ${ }^{15}{ }^{18-20}$ The injury definition and data-collection procedure are in accordance with the respective consensus statement. ${ }^{21}$ An injury was defined as any physical complaint during a match which received medical attention from the team physician, regardless of the consequences with respect to absence from match or training. ${ }^{21}$ The physicians of all participating teams reported all injuries after each match on a standardised injury report form. Details of the methodology are published elsewhere. ${ }^{15} 1718$

\section{Calculation of injury rates and statistical analysis} Injury rates were expressed per match, per 1000 player hours and per 1000 player matches. Player hours were calculated by multiplying the number of returned injury report forms by five players by $40 / 60 \mathrm{~h}$. Extra time and reduced numbers of players on the field were not taken into account because only few matches went into extra time, and the exclusion of a player is a rare exception. ${ }^{15}$ Injuries per 1000 player hours were calculated: number of injuries multiplied by 1000 divided by total player hours. Player 
matches were calculated by multiplying number of returned injury report forms by five players. Injuries per 1000 player matches were calculated: number of injuries multiplied by 1000 divided by total player matches. For incidence rates, $95 \%$ CIs were calculated as the incidence \pm 1.96 times the incidence divided by the square root of the number of injuries. Statistical methods applied were frequencies, crosstabulations and $\chi^{2}$ test. Significance was accepted at the $5 \%$ level.

\section{Tournaments}

Three consecutive Futsal World Cups (2000, 2004, 2008) were included in the present study. These tournaments comprised 136 matches, equivalent to 906.7 player hours (table 2). A total of 253 injury report forms, covering 843 player hours, were completed and returned. The mean response rate was $93 \%$.

Table 1 Differences in the laws of the game between football and futsal

\begin{tabular}{|c|c|c|}
\hline & Football & Futsal \\
\hline Pitch & $90-120 \times 45-90 \mathrm{~m}$ & $38-42 \times 18-25 \mathrm{~m}$ \\
\hline Ball & $\begin{array}{l}410-450 \mathrm{~g}, \\
\text { circumference } 68-70 \mathrm{~cm}\end{array}$ & $\begin{array}{l}400-440 \mathrm{~g} \text {, circumference } 62-64 \\
\mathrm{~cm}\end{array}$ \\
\hline Players per team & 11 & 5 \\
\hline \multirow[t]{2}{*}{ Substitutions } & 3 & $\begin{array}{l}\text { Unlimited 'flying' (12 players on } \\
\text { a team) }\end{array}$ \\
\hline & $\begin{array}{l}\text { No substitution for player } \\
\text { sent off }\end{array}$ & $\begin{array}{l}\text { Player sent off can be substituted } \\
\text { for after } 2 \text { min or other has scored }\end{array}$ \\
\hline \multirow[t]{2}{*}{ Duration } & 45 min halves & 20 min halves \\
\hline & Running clock & Stopped clock \\
\hline Time-outs & No time-outs & 1 time-out per half and team \\
\hline \multirow[t]{2}{*}{ Restart the match } & No absolute time limit & $4 \mathrm{~s}$ rule on restarts \\
\hline & Throw-in & Kick-in \\
\hline Offside rule & Yes & No \\
\hline Accumulated fouls & No & Yes \\
\hline
\end{tabular}

\section{RESULTS}

A total of 165 injuries were reported from the three tournaments, which is equivalent to an incidence of 1.30 injuries per match (95\% CI 1.10 to 1.50), 195.6 injuries per 1000 player hours (95\% CI 165.8 to 225.6) or 130.4 injuries per 1000 player matches (95\% CI 110.5 to 150.3). The injury rate was similar in both halves, and in the first and second 10 min periods of both halves.

Most injuries were caused by contact with another player, and $36 \%$ of the injuries occurred during non-contact activities. Less than half (46\%) of the contact injuries (43 of 93), or $26 \%$ of all injuries, were caused by foul play based on the judgement of the team physician, but about two-thirds of these (27 of 43) were followed by a sanction of the referee.

The injuries affected the lower extremity ( $n=115 ; 69.7 \%)$ most frequently, followed by head and neck ( $n=21,12.7 \%)$, upper extremity $(n=17 ; 10.3 \%)$ and trunk $(n=12 ; 7.3 \%)$. The body parts predominantly injured were knee ( $n=26 ; 15.8 \%)$, thigh ( $n=23 ; 13.9 \%)$, ankle and lower leg (each $n=20 ; 12.1 \%$ ). Most injuries were diagnosed as contusions ( $n=73 ; 44.2 \%$ ), sprains or ligament ruptures $(n=32 ; 19.4 \%)$ and strains or muscle fibre ruptures $(n=29 ; 17.6 \%)$. Seven injuries were diagnosed as concussion, three as ligament rupture in the knee, two as fracture (finger and foot) and one as a lesion of the meniscus (table 3 ). The most frequent diagnoses were contusion of the lower leg $(n=18 ; 10.9 \%)$, ankle sprain $(n=16 ; 9.7 \%)$ and groin strain ( $n=13 ; 7.9 \%)$.

Information in relation to time loss in sport was available for 138 (84\%) injuries. At least 67 injuries (48.6\%) were expected to prevent the player from participating in match or training. The incidence of time-loss injuries was 79.5 per 1000 player hours (95\% CI 59.7 to 98.5 ), 53.0 per 1000 player matches $(95 \%$ CI 40.3 to 65.7$)$ or approximately one in every two matches. The most prevalent diagnoses of time-loss injuries were groin and thigh strains and ankle sprains (each $\mathrm{n}=8 ; 11.9 \%$ ).

Table 2 Incidence and characteristics of injuries in Futsal World Cups 2000-2008

\begin{tabular}{|c|c|c|c|}
\hline Tournament & Guatemala $2000^{15}$ & Chinese Taipei 2004 & Brazil 2008 \\
\hline No of matches & 40 & 40 & 56 \\
\hline Injury report forms returned & $66(82.5 \%)$ & $80(100 \%)$ & 107 (95.5\%) \\
\hline Player hours documented & 220 & 266.7 & 356.7 \\
\hline No of injuries & 42 & 63 & 60 \\
\hline Per 1000 player hours $(95 \% \mathrm{CI})$ & 190.9 (133.1 to 248.7$)$ & $236.0(177.8$ to 294.2$)$ & 168.5 (125.8 to 211.2$)$ \\
\hline Per 1000 player matches $\quad(95 \% \mathrm{Cl})$ & 127 (88.6 to 165.4$)$ & $158(119.0$ to 197.0$)$ & 111 (83.0 to 149.0$)$ \\
\hline Circumstances & $\mathrm{N}(\%)$ & $\mathrm{N}(\%)$ & $\mathrm{N}(\%)$ \\
\hline Non-contact injuries & 10 of $41(24 \%)$ & 19 of $58(33 \%)$ & 28 of $58(48 \%)$ \\
\hline Contact injuries & 31 of $41(76 \%)$ & 39 of $58(67 \%)$ & 30 of $58(52 \%)$ \\
\hline Contact-injury caused by foul & 14 of $27(52 \%)$ & 25 of $39(64 \%)$ & 4 of $27(15 \%)$ \\
\hline Foul sanctioned by the referee & 6 of $13(46 \%)$ & 18 of $25(72 \%)$ & 3 of $4(75 \%)$ \\
\hline Estimated severity of injury & $\mathrm{N}(\%)$ & $\mathrm{N}(\%)$ & $\mathrm{N}(\%)$ \\
\hline 0 days & $21(53.3 \%)$ & $29(64 \%)$ & $21(41 \%)$ \\
\hline $1-3$ days & $12(31.6 \%)$ & $8(18 \%)$ & $23(43 \%)$ \\
\hline 4-7 days & $1(2.6 \%)$ & $6(13 \%)$ & $0(0 \%)$ \\
\hline$>1$ week $<1$ month & $3(7.9 \%)$ & $2(3 \%)$ & $8(15 \%)$ \\
\hline$>1$ month & $1(2.6 \%)$ & - & $1(2 \%)$ \\
\hline Missing & 4 & 18 & 7 \\
\hline Time-loss injuries* & 17 & 18 & 32 \\
\hline Per 1000 player hours & $\geq 77.2$ & $\geq 67.5$ & $\geq 89.9$ \\
\hline (95\% CI) & $(40.5$ to 113.9$)$ & (22.3 to 98.7 ) & (58.8 to 121.0$)$ \\
\hline Per 1000 player matches & $\geq 52$ & $\geq 45$ & $\geq 60$ \\
\hline (95\% Cl) & (27.3 to 76.7$)$ & (24.2 to 65.8$)$ & (39.2 to 80.8$)$ \\
\hline
\end{tabular}

*Information on time loss from sport is missing in 27 injuries. 
Table 3 Diagnosis of injuries in FIFA Futsal World Cups 2000-2008

\begin{tabular}{|c|c|c|c|}
\hline \multirow[b]{2}{*}{ Location and type } & \multicolumn{3}{|c|}{ No of injuries } \\
\hline & Total* & Without absence & With absence \\
\hline Head/neck & $21(12.7 \%)^{*}$ & 16 (13.9\%) & $4(6.0 \%)$ \\
\hline Concussion & $7^{*}$ & 4 & 2 \\
\hline Sprain & 4 & 4 & 0 \\
\hline Contusion & 8 & 8 & 0 \\
\hline Laceration & 2 & 0 & 2 \\
\hline Trunk & $12(7.3 \%)$ & $6(8.3 \%)$ & $6(9.0 \%)$ \\
\hline Strain & 2 & 0 & 2 \\
\hline Contusion & 6 & 5 & 1 \\
\hline Laceration & 2 & 1 & 1 \\
\hline Others & 2 & 0 & 2 \\
\hline Upper extremity & $17(10.3 \%)^{*}$ & $13(18.1 \%)$ & $3(4.5 \%)$ \\
\hline Fracture & 1 & 1 & 0 \\
\hline Sprain & 3 & 2 & 1 \\
\hline Contusion & $10^{*}$ & 9 & - \\
\hline Others & 3 & 1 & 2 \\
\hline Hip/groin & $17(10.3 \%)^{*}$ & $8(11.1 \%)$ & $8(11.9 \%)$ \\
\hline Strain (all groin) & 13 & 5 & 8 \\
\hline Others (all hip) & $4^{*}$ & 3 & - \\
\hline Thigh & $23(13.9 \%)^{*}$ & $3(4.2 \%)$ & $15(22.4 \%)$ \\
\hline Strain & 9 & 1 & 8 \\
\hline Contusion & $10^{*}$ & 2 & 3 \\
\hline Others & 4 & 0 & 4 \\
\hline Knee & $26(15.8 \%)^{*}$ & $6(8.3 \%)$ & $14(20.9 \%)$ \\
\hline Ligament rupture & $3^{*}$ & - & 2 \\
\hline Lesion of meniscus & 1 & - & 1 \\
\hline Sprain & $9^{*}$ & 1 & 6 \\
\hline Contusion & $10^{*}$ & 4 & 3 \\
\hline Others & 3 & 1 & 2 \\
\hline Lower leg & $20(12.1 \%)^{*}$ & $11(15.3 \%)$ & $5(7.5 \%)$ \\
\hline Contusion & $18^{*}$ & 9 & 5 \\
\hline Strains & 2 & 2 & 0 \\
\hline Ankle† & $20(12.1 \%)^{*}$ & $6(8.3 \%)$ & $9(13.4 \%)$ \\
\hline Sprain & $16^{*}$ & 5 & 8 \\
\hline Contusion & $3^{*}$ & 1 & 1 \\
\hline Foot/toe & $9(5.5 \%)^{*}$ & $3(4.2 \%)$ & $3(4.5 \%)$ \\
\hline Fracture & 1 & 0 & 1 \\
\hline Strain & 1 & 0 & 1 \\
\hline Contusion & $7^{*}$ & 3 & 1 \\
\hline
\end{tabular}

*Information on time loss from sport is missing in at least one injury (total: 27 injuries).

tInformation on type is missing in one case.

\section{DISCUSSION}

This present study is the first survey of the incidence and characteristics of injuries in top-level futsal players. The methodology applied is well established, and its strengths and weaknesses have been discussed previously. ${ }^{15} 18$

During the three recent FIFA Futsal World Cups, the team physicians reported 165 injuries, equivalent to 195.6 injuries per 1000 player hours (95\% CI 165.8 to 225.6). This injury rate was 2.6 times higher than the average of the FIFA World Cups $1998,{ }^{15} 2002^{19}$ and $2006^{20}$ (74.2; 95\% CI 67.5 to 80.9). A higher exposure-time related injury rate in futsal compared with football was also reported from a national survey on sports injuries in The Netherlands. ${ }^{8}$ However, football is played with a running clock, while in futsal the clock is stopped when the ball is out of play (see table 1). Junge et a ll $^{17}$ have previously discussed the methodological dilemma when comparing injury incidences of different sports and concluded that it is more adequate to compare the injury rate in relation to 'athlete's exposures' or for team sports: player matches. ${ }^{17} 22$ The injury incidence per 1000 player matches was similar in the Futsal and the Football World Cups (111.2; 95\% CI 101.1 to 121.3). Almost half (48.6\%) of the injuries incurred in the Futsal Word Cups were expected to prevent the player from participating in match or training but two-thirds (68\%) in the equivalent football competitions. Thus, the incidence of time-loss injuries per 1000 player matches was significantly lower in the Futsal than in the Football World Cups (72.4; 95\% CI 62.3 to 82.5).

Similar to football injuries, ${ }^{67}$ most injuries in the present study were incurred by contact with another player and affected the lower extremity. However, a more detailed comparison of injuries incurred in the Futsal and the FIFA World Cups showed that a higher percentage of futsal than football injuries were incurred without contact with another player ( $37 \%$ vs $27 \%$ ). In addition, in futsal, fewer contact injuries were caused by foul play than in football ( $46 \%$ vs $56 \%$ ), probably because futsal referees punished injury-causing fouls more frequently than football referees ( $64 \%$ vs $55 \%$ ).

The majority of injuries affected the lower extremity, and the most frequent diagnoses were contusions of the lower leg and ankle sprain, as reported previously for elite male football players. ${ }^{67}$ In addition, groin strains were among the three most common time-loss injuries which is different from top-level football competitions. ${ }^{15} 192023$ It can be assumed that multiple sprints with frequent changes in direction contribute to the higher proportion of non-contact injuries, such as groin strains.

Seven concussions were reported from the three Futsal World Cups compared with six in the three football world cups. If these figures are related to the number of player matches, the incidence of concussions was 3.6 times higher in futsal than in football (5.15 vs 1.42 per 1000 player matches, NS). In the present study, all concussions were caused by contact with another player, and half of the injury situations were classified as foul play by the team physicians compared with $26 \%$ of all injuries. In international football, video analysis of the injury situation has shown that the (unfair) use of the arm to tackle the opposing player during vertical jumps was most likely to cause a head or neck injury, but none of the incidents resulting in a concussion was deemed to be a foul by the match referee. ${ }^{24}$ Based on the results of that study, the referees of the 2006 FIFA World Cup ${ }^{\mathrm{TM}}$ were encouraged to severely sanction injurious fouls such as intentional elbows to the head. In the 2006 FIFA World Cup ${ }^{\mathrm{TM}}$, only one concussion occurred, compared with four in 2002, and the total number of head injuries dropped from 25 to $13 .{ }^{20}$

Future studies should investigate injury mechanisms in futsal using video analysis, which has provided valuable information about injury mechanisms in professional male football players. ${ }^{25} 26$ Such analysis may provide additional information to develop preventive interventions to reduce the incidence of injury in futsal competitions.

The present study on injuries during top-level competitions and a Dutch national survey ${ }^{8}$ showed that injuries are frequent in futsal. In light of the growing popularity of futsal, future studies should evaluate the incidence, characteristics and causation of injuries on all levels of play during the season as a basis for the development of injury-prevention programmes.

\section{CONCLUSION}

The exposure-time-related incidence of injury in world cups was higher in futsal than in football, but the risk of a time-loss 


\section{What is already known on this topic}

- Futsal is a popular sport in many countries, and a Futsal World Cup takes place every 4 years.

- There is only one study on the incidence of futsal injury, and this stated that futsal was among the top 10 sports that contributed most to the absolute number of sports injuries in The Netherlands.

- In this national survey on sports injuries in The Netherlands, futsal had the highest injury incidence per $10000 \mathrm{~h}$ of sports participation.

\section{What this study adds}

- Based on exposure time, the incidence of injury in world cups is higher in futsal than in football, but the risk of a time-loss injury per player match was lower in futsal than in football.

- The majority of injuries were incurred due to contact with another player as reported previously for match injuries of football players, but in contrast to the corresponding tournaments of male football players, fewer futsal injuries were caused by foul play.

- The location and type of injuries were similar in football and futsal, but groin strains were more frequent in the Futsal than in the Football World Cups.

- More information on the incidence, characteristics and causation of futsal injuries on all levels of play during the season are required to develop specific injury-prevention programmes.

injury in relation to player matches was lower. While the location and type of injuries were similar between the two ways of playing football, the injury mechanism varied with fewer futsal than football injuries caused by contact with another player and by foul play. However, concussions are frequent in futsal and (too) often caused by unfair tackles. More information on injury mechanisms in futsal is needed to develop specific injury-preventive interventions.

Acknowledgements The authors highly appreciate the cooperation of all team physicians who volunteered their time to collect the data for this project. The authors thank R Charles and A König, for their help with the data collection, and D O'Riordan, for his assistance in preparing the manuscript.

Funding The authors gratefully acknowledge Fédération Internationale de Football Association for the funding of this study.

\section{Competing interests None.}

Ethics approval Ethics approval was provided by the University of Zurich, Switzerland.

Provenance and peer review Not commissioned; externally peer reviewed.

\section{REFERENCES}

1. Barbieri FA, Gobbi LT, Santiago PR, et al. Performance comparisons of the kicking of stationary and rolling balls in a futsal context. Sports Biomech 2010;9:1-15

2. Alvarez JC, D'Ottavio S, Vera JG, et al. Aerobic fitness in futsal players of different competitive level. J Strength Cond Res 2009;23:2163-6.

3. Tessitore A, Meeusen R, Pagano R, et al. Effectiveness of active versus passive recovery strategies after futsal games. J Strength Cond Res 2008;22:1402-12.

4. Castagna C, D'Ottavio S, Granda Vera J, et al. Match demands of professional Futsal: a case study. J Sci Med Sport 2009;12:490-4.

5. Barbero-Alvarez JC, Soto VM, Barbero-Alvarez V, et al. Match analysis and heart rate of futsal players during competition. J Sports Sci 2008;26:63-73.

6. Junge A, Dvorak J. Soccer injuries: a review on incidence and prevention. Sports Med 2004;34:929-38.

7. Giza E, Micheli LJ. Soccer injuries. Med Sport Sci 2005;49:140-69.

8. Schmikli SL, Backx FJ, Kemler HJ, et al. National survey on sports injuries in The Netherlands: target populations for sports injury prevention programs. Clin J Sport Med 2009;19:101-6.

9. Cain LE, Nicholson LL, Adams RD, et al. Foot morphology and foot/ankle injury in indoor football. J Sci Med Sport 2007;10:311-19.

10. Hoff GL, Martin TA. Outdoor and indoor soccer: injuries among youth players. Am J Sports Med 1986;14:231-3.

11. Putukian M, Knowles WK, Swere S, et al. Injuries in indoor soccer. The Lake Placid Dawn to Dark Soccer Tournament. Am J Sports Med 1996;24:317-22.

12. Lindenfeld TN, Schmitt DJ, Hendy MP, et al. Incidence of injury in indoor soccer. Am J Sports Med 1994;22:364-71.

13. Emery CA, Meeuwisse WH. The effectiveness of a neuromuscular prevention strategy to reduce injuries in youth soccer: a cluster-randomised controlled trial. Br J Sports Med 2010;44:555-62.

14. Emery CA, Meeuwisse WH. Risk factors for injury in indoor compared with outdoor adolescent soccer. Am J Sports Med 2006;34:1636-42.

15. Junge A, Dvorak J, Graf-Baumann T, et al. Football injuries during FIFA tournaments and the Olympic Games, 1998-2001: development and implementation of an injury-reporting system. Am J Sports Med 2004;32(1 Suppl):80S-9S.

16. Langevoort G, Myklebust G, Dvorak J, et al. Handball injuries during major international tournaments. Scand J Med Sci Sports 2007;17:400-7.

17. Junge A, Langevoort G, Pipe A, et al. Injuries in team sport tournaments during the 2004 Olympic Games. Am J Sports Med 2006;34:565-76.

18. Junge A, Dvorak J. Injuries in female football players in top-level international tournaments. Br J Sports Med 2007;41(Suppl 1):i3-7.

19. Junge A, Dvorak J, Graf-Baumann T. Football injuries during the World Cup 2002 Am J Sports Med 2004;32(1 Suppl):23S-7S.

20. Dvorak J, Junge A, Grimm K, et al. Medical report from the 2006 FIFA World Cup $^{\top M}$ Germany. Br J Sports Med 2007:41:578-81; discussion 581.

21. Fuller CW, Ekstrand J, Junge $A$, et al. Consensus statement on injury definitions and data collection procedures in studies of football (soccer) injuries. Br J Sports Med 2006;40:193-201.

22. Junge A, Engebretsen L, Alonso JM, et al. Injury surveillance in multi-sport events: the International Olympic Committee approach. Br J Sports Med 2008;42:413-21.

23. Ekstrand J, Timpka T, Hägglund M. Risk of injury in elite football played on artificial turf versus natural grass: a prospective two-cohort study. Br J Sports Med 2006;40:975-80.

24. Fuller CW, Junge A, Dvorak J. A six year prospective study of the incidence and causes of head and neck injuries in international football. Br J Sports Med 2005;39(Suppl 1):i3-9.

25. Fuller CW, Smith GL, Junge A, et al. The influence of tackle parameters on the propensity for injury in international football. Am J Sports Med 2004;32:43S-53S

26. Andersen TE, Larsen $\emptyset$, Tenga A, et al. Football incident analysis: a new video based method to describe injury mechanisms in professional football. Br J Sports Med 2003;37:226-32. 